\title{
Age structure of non-native fish species, Cyprinus carpio (Linnaeus, 1758) from the tributary of the Ganga river, India
}

\begin{abstract}
Cyprinus carpio (e.g. culture and wild/capture) constitute a large part of daily meal of human population in Indian sub-continent. It shows benthic and sedentary behavior. Age structure of C. carpio was studied during February 2019 to January 2020 from fish landing centre at Sirsa, Prayagraj, Uttar Pradesh, India. The key scales were studied for estimation of age structure in the present study. A total of 548 fish specimens in length ranges between 97 to $687 \mathrm{~mm}$ and age classes of $0+$ to $9+$ were observed. Age structures were determined for male, female and pooled samples separately. The 1+ age group was most dominating stock with shared $23.53 \%, 24.64 \%$ and $24.09 \%$ in case of male, female and pooled samples, respectively. The age group $2+$ was second dominating age class and this age class more attracted to fishermen for the exploitation. In case of pooled sample, $1+$ age group was also dominated compared to $2+$ and $3+$ age groups. The old age groups of fishes were shared very minute proportion in the total stock. Present study was also indicated that the female fishes live longer than male from the Tons river at Prayagraj, India.
\end{abstract}

Keywords: age structure, cyprinus carpio, stock, male fishes, female fishes, tons river
Volume 10 Issue 2 - 2021

\author{
Amitabh Chandra Dwivedi,' Neeti Mishra ${ }^{2}$ \\ 'Department of Zoology, Nehru Gram Bharati (Deemed to be \\ University), India \\ ${ }^{2}$ Kalash Research and Welfare Society, India
}

Correspondence: Amitabh Chandra Dwivedi, Department of Zoology, Nehru Gram Bharati (Deemed to be University), India, Email saajjjan@rediffmail.com

Received: March 31, 2021 | Published: April 26, 2021

\section{Introduction}

Fisheries of the Ganga river basin (Example non-native speciesCyprinus carpio (Common carp) and Oreochromis niloticus (Nile Tilapia) are very vital for the livelihood of fishers/fishermen near the river bank and fish sellers, India. ${ }^{1-4}$ Fishes play a key role in the productivity of aquatic ecosystems while non-native fishes may change ecosystem functioning directly. ${ }^{5-7}$ The quantity in respect of number of the fish caught in many of the world's rivers is declining and species assemblages are being modified with the disappearance of some native species and the established of exotics. ${ }^{8-12}$

C. carpio is a large size and fast growing fish species with are netted in large numbers from the rivers, reservoirs and lakes. ${ }^{13-17} \mathrm{It}$ is back bone of capture fishery in the Ganga basin, India. ${ }^{18-19} \mathrm{~A}$ lot of freshwater ecosystems suffer from dense stock of C.carpio. ${ }^{5}$, ${ }^{20-21}$ It is one of the most economically important fish species in the globe. C. carpio prefer larger and slow moving water bodies with soft sediments. ${ }^{12,22}$ They are highly liberal and hardy fish that thrive in a wide variety of aquatic habitats. ${ }^{3,23-24}$

C. carpio is commonly also called an ecological pest because it can change ecological characteristics. These characters have supports to the introduction of the species in many parts of Asia and Europe. $C$. carpio is reformed to their own set of local ecological base, climatic conditions and fish composition (Example homogenize native fish communities). ${ }^{21,25-26}$ They are altering biodiversity (example biodiversity of fishes). It is dominating species from the Ganga river, Yamuna river and its tributaries, India. ${ }^{17,27}$ The study would help the fishery managers and planners in management of $C$. carpio fishery in respect of Indian major carp (Catla catla, Labeo rohita, Cirrhinus mrigala) of the river.

\section{Material and methods}

The Tons river is a right bank tributary of the Ganga river which forms confluence at Sirsa near Meja in the Prayagraj district, Uttar Pradesh. The fish samples of C. carpio were collected during February 2019 to January 2020 from fish landing centre at Sirsa, Prayagraj, Uttar Pradesh, India. Fishes were collected using a variety of methods including gill nets, drag nets, cast nets and hook and lines. Samples of key scales from 548 fish specimens in the length ranges between 97 to $687 \mathrm{~mm}$ were examined for determination of age class and age structure. The total length of each fish (in $\mathrm{mm}$, from the tip of snout and the end of longest caudal fin rays) was measured and recorded. The key scales were removed from the region just below the dorsal fin ( 3 to 4 rows) and above the lateral line. ${ }^{28-31}$

The scales were cleaned in $5 \% \mathrm{KOH}$ solution to remove adheringtissues and finally washed in distilled water. The scales were then pressed while drying in order to avoid their curling. The season with "minimum width in the terminal part of the anterior field of the scale" was designated as the period of ring formation. Since this condition occurred only once a year, the ring was designated as annuli. The total length and growth rate were recorded as differences between-at-age. The number of fishes in each age class was converted into percentage to obtain age structure.

\section{Result and discussion}

Age structures were determined for male, female and pooled samples separately from the Tons river at Prayagraj, India. Age classes of $C$. carpio varied from $0+$ to $9+$ years. The $1+$ age group was most dominating stock with shared $23.53 \%$ and $24.64 \%$ in case of male and female, respectively (Table 1 ). The age group $2+$ was second 
dominating age class and this age class more attracted to fishermen for exploitation. After 2+ age group exploitation was decreased with increase of the age of fishes.

In case of male, age classes $0+, 2+, 3+, 4,5+, 6+$ and $7+$ were shared $7.35 \%, 20.95 \%, 18.38 \%, 13.60 \%, 7.35 \%, 4.41 \%$ and $2.57 \%$, respectively (Table 1, Figure 1a). In case of female, age classes $0+, 2+$
$3+, 4,5+, 6+, 7+, 8+$ and $9+$ were contributed $6.16 \%, 21.74 \%, 18.84 \%$, $14.13 \%, 8.33 \%, 3.26 \%, 1.81 \%, 0.72 \%$ and $0.36 \%$, respectively (Table 1 , Figure $1 \mathrm{~b}$ ). The old age groups of fishes were shared very minute proportion, in male, female and pooled samples. Present study was also indicated that the female fishes live longer than male from the Tons river at Prayagraj, India. In pooled samples, $1+$ age group was also dominated compared to $2+$ and $3+$ age groups (Table 1 ).

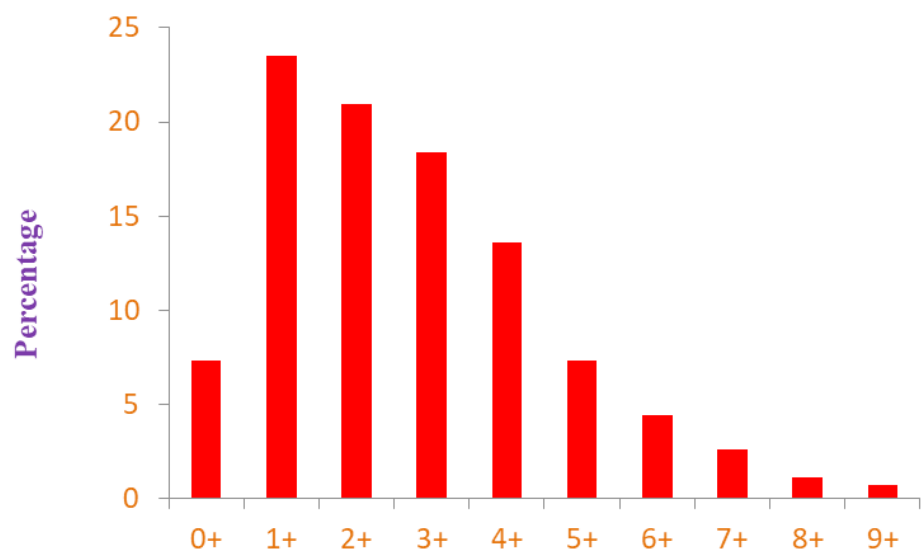

Age Classes

Figure Ia Age structure of Cyprinus carpio from the Tons river, India (Male samples).

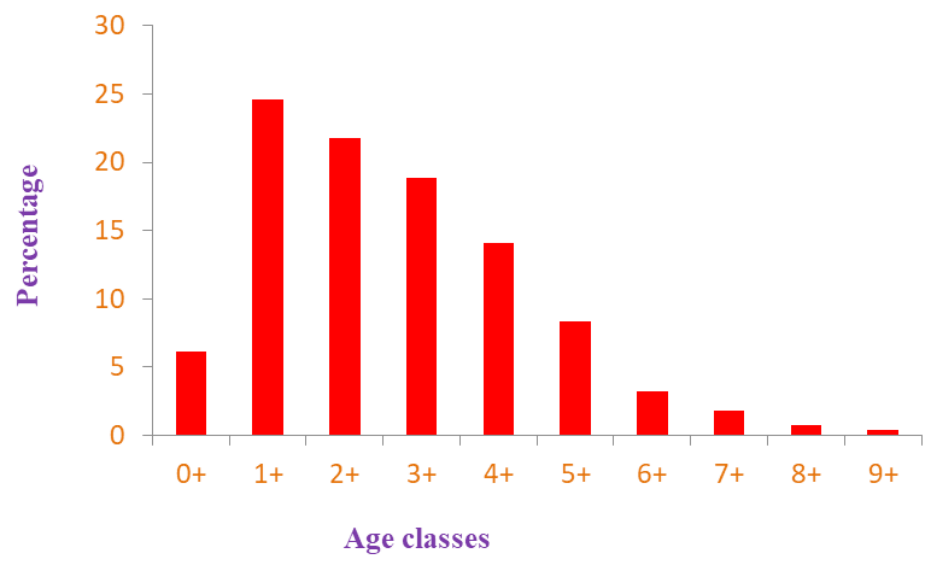

Figure Ib Age structure of Cyprinus carpio from the Tons river, India (Female samples).

Table I Age structure of Cyprinus carpio from the tons river at Prayagraj, India

\begin{tabular}{llllll}
\hline Age classes & No. of male & Percentage & No. of female & Percentage & No. of Pooled sample \\
\hline $0+$ & 20 & 7.35 & 17 & 6.16 & 37 \\
$1+$ & 64 & 23.53 & 68 & 24.64 & 132 \\
$2+$ & 57 & 20.95 & 60 & 21.74 & 117 \\
$3+$ & 50 & 18.38 & 52 & 18.84 & 102 \\
$4+$ & 37 & 13.60 & 39 & 14.13 & 76 \\
$5+$ & 20 & 7.35 & 23 & 8.33 & 43 \\
$6+$ & 12 & 4.41 & 9 & 3.26 & 21 \\
$7+$ & 7 & 2.57 & 5 & 1.81 & 12 \\
$8+$ & 3 & 1.11 & 2 & 0.72 & 5 \\
$9+$ & 2 & 0.73 & 1 & 0.36 & 3 \\
Total & 272 & & 276 & & 548
\end{tabular}


Basic frameworks for the altering of age structure of fishes in the lotic environment in the Tons river. The conceptual framework process runs by ecological condition, ecosystem function and ecosystem services. Habitat change and loss is one of the most important derivers for the decreasing of age structure. Note that altered age structure was also recorded by invasion of non-native fish species (Figure 2). The size of the net and size of the mesh was very effective factors for the decreasing of the age structure of $C$. carpio from the Tons river, India. A lot of fishers were used very small mesh size of the net with very large size of the net. In this type of fishing, directly effect on the stock of juveniles and brooders. For healthy stock and heavy recruitment, the number of juvenile and brooder should be greater than middle age class samples. ${ }^{11,32-33}$

The large and old age fishes protect for reaping ecology and fishery productivity in the large water bodies especially streams and rivers. ${ }^{34-36}$ The state of the age structure is a valuable indicator of how the fished stocks are reacting to the pressures of fishing and stressors. ${ }^{37-39}$

\section{Pollution load especially inorganic}

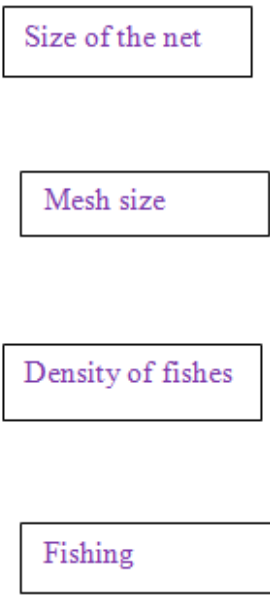

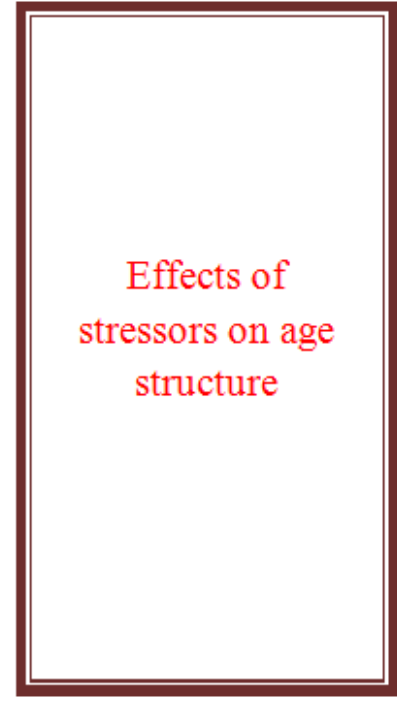

Accumulation of heavy metals
Rate of the recruitments

Fishing mortality

Natural mortality

Stock of non-native species

Figure 2 Basic frameworks for altering of age structure of fishes. The conceptual framework process runs by ecological condition, ecosystem function and ecosystem services. Habitat change and loss is one of the most important derivers for the decreasing of age structure.

\section{Conflicts of interest}

The author declares that there are no conflicts of interest.

\section{Funding}

None.

\section{Acknowledgments}

None.

\section{References}

1. Pathak RK, Gopesh A, Dwivedi AC. Alien fish species, Cyprinus carpio var. communis (common carp) as a powerful invader in the Yamuna river at Allahabad, India. National Academy of Science Letter. 2011;34(9 \& 10):367-373.

2. Mayank P, Dwivedi AC. Biology of Cirrhinus mrigala and Oreochromis niloticus. LAP LAMBERT Academic Publishing GmbH \& Co. KG, Dudweiler Landstr. 99, 66123 Saarbrucken, Germany, 2015; 188 p.
3. Dwivedi AC, Mishra AS, Mayank P, et al. Persistence and structure of the fish assemblage from the Ganga river (Kanpur to Varanasi section), India. Journal of Geography and Natural Disasters. 2016;6(1):159.

4. Tripathi S, Gopesh A, Dwivedi AC. Framework and sustainable audit for the assessing of the Ganga river ecosystem health at Allahabad, India. Asian Journal of Environmental Science. 2017;12(1):37-42.

5. Vilizzi L, Tarkan AS, Copp GH. Experimental evidence from causal criteria analysis for the effects of Common carp Cyprinus carpio on freshwater ecosystems: A global perspective. Reviews in Fisheries Science \& Aquaculture. 2015; 23:253-290.

6. Tiwari A, Dwivedi AC, Mayank P. Time scale changes in the water quality of the Ganga River, India and estimation of suitability for exotic and hardy fishes. Hydrology Current Research. 2016;7(3):254.

7. Nautiyal P, Dwivedi AC. Fishery in the tributaries of Yamuna river (Ken river, Paisuni river) and Ganga river (Tons river). Journal of Mountain Research. 2019;14(2):19-36.

8. Welcomme RL. Improving the productivity of flood plains through fishery management. International Journal of Ecology and Environmental Science. 2006;32(1):15-23. 
9. Weber MJ, Brown ML, Wills DW. Spatial variability of common carp populations in relation to lake morphology and physicochemical parameters in upper Midwest United States. Ecology of Freshwater Fishes. 2010;19(4):555-565.

10. Villéger S, Blanchet S, Beauchard O, et al. From current distinctiveness to future homogenization of the world's freshwater fish faunas. Diversity \& Distribut.2015;21(2)1-13.

11. Dwivedi AC, Mayank P, Tiwari A. Size selectivity of active fishing gear: changes in size, age and growth of Cirrhinus mrigala from the Ganga River, India. Fisheries and Aquaculture Journal. 2017; 8(2):1-5.

12. Mishra N, Dwivedi AC. Environmental derivers supports to distribution, composition and biology of Cyprinus carpio (Linnaeus, 1758) in respect of time scale: A review. Journal of the Kalash Science. 2020;8(2):91-102.

13. Vilizzi L, Walker KD. Age and growth of the common carp, Cyprinus carpio, in the river Murry, Australia: validation consistency of age interpretation and growth models. Environmental Biology of Fishes. 1999;54:77-102.

14. Mirza ZS, Nadeem MS, Beg MA, Qayyum M. Population Status and Biological Characteristics of Common Carp, Cyprinus carpio, in Mangla Reservoir (Pakistan). J Anim Plant Sci. 2012;22:933-938.

15. Dwivedi AC, Mayank P, Tiwari A. The River as transformed by human activities: the rise of the invader potential of Cyprinus carpio and Oreochromis niloticus from the Yamuna River, India. Journal of Earth Science \& Climatic Change. 2016;7(7):361.

16. Dwivedi AC, Mayank P, Tripathi S, et al. Biodiversity: the non-natives species versus the natives species and ecosystem functioning. Journal of Biodiversity, Bioprospecting and Development. 2017;4(1):1-8.

17. Tripathi SA, Gopesh AC, Dwivedi. Fish and fisheries in the Ganga river: current assessment of the fish community, threats and restoration. Journal of Experimental Zoology, India. 2017;20(2): 907-912.

18. Jha DN, Joshi KD, Dwivedi AC, et al. Assessment of fish production potential of Chitrakoot district, Uttar Pradesh. Journal of the Kalash Science. 2015; 3(3, Special Volume): 7-10.

19. Dwivedi AC, Jha D N, Shrivastava RS, et al. Status of water resources and fish farming in Allahabad district, India. Journal of Fisheries and Livestock Production. 2018;6(3):274.

20. Arlinghaus R, Mehner T. Socio-economic charecterisation of specialized of specialized common carp (Cyprinus carpio L.) anglers in Germany and implications for inland fisheries management and eutrophication control. Fish Research. 2003;61(1): 19-33.

21. Mayank P, Dwivedi AC. Role of exotic carp, Cyprinus carpio and Oreochromis niloticus from the lower stretch of the Yamuna river. In: Advances in biosciences and Technology edited by K.B. Pandeya, A.S. Mishra R.P. Ojha and A.K. Singh published by NGBU, Allahabad. 2015;93-97.

22. Balon EK. The common carp, Cyprinus carpio: its wild origin, domestication in aquaculture and selection as colored nishikigoi. Guelpd Ichthyol. Rev. 1995;3:1-55.

23. Froese R, Pauly D. Fish base: Species summary for Cyprinus carpio (Online). 2002.

24. Dwivedi AC, Mayank P, Masud S, et al. An investigation of the population status and age pyramid of Cyprinus carpio var. communis from the Yamuna river at Allahabad. The Asian Journal of Animal Science. 2009;4(1):98-101.
25. Rahel FJ. Homogenization of fish faunas across the United States. Science. 2000;288:854-856.

26. Dwivedi AC, Mishra AS, Mayank P, et al. Resource use competence and invader potential of Cyprinus carpio from the Paisuni river at Bundelkhand region, India. Journal of Nehru Gram Bharati University. 2019;8(01):20-29.

27. Dwivedi AC, Tiwari A, Mayank P. Environmental pollution supports to constancy and invader potential of Cyprinus carpio and Oreochromis niloticus from the Ganga river, India. International Journal of Poultry and Fisheries Sciences. 2018;2(2): 1-7.

28. Bagenal TB, Tesch FW. Age and growth. In: Bagenal TB. Editor. Methods for assessment of fish production in freshwater, 3rd edn. Blackwell Scientific Publication, Oxford, UK. 1978;101-136.

29. Mayank P, Dwivedi AC, Pathak RK. Age, growth and age pyramid of exotic fish species Oreochromis niloticus (Linnaeus 1758) from the lower stretch of the Yamuna river, India. National Academy Science Letter. 2018;41(6):345-348.

30. Dwivedi AC, Mayank P. Studies on the age, growth pattern and sex ratio of Cyprinus carpio var. communis from the largest tributary of the Ganga river, India. Journal of the Kalash Science. 2013;Special Volume: 21-27.

31. Nautiyal P, Dwivedi AC. Growth rate determination of the endangered Mahseer, Tor tor (Hamilton 1822) from the Bundelkhand region, central India. Journal of Fisheries Research. 2020;4(2):7-11.

32. Dwivedi AC, Khan S, Mayank P. Stressors altering the size and age of Cirrhinus mrigala (Hamilton, 1822) from the Ghaghara River, India. Oceanography Fish Open Access Journal. 2017;4(4):555642.

33. Nautiyal P, Dwivedi AC, Shivam A, Singh KR. Possibility of breeding grounds of Mahseer in the Paisuni R. (Chitrakoot Dham): its ecology, and status of Tor tor (Hamilton) in the north Vindhyan rivers. Journal of the Bombay Natural History Society. 2007;104(3):355-357.

34. Berkeley SA, Hixon MA, Larson RJ, et al. Fisheries sustainability via protection of age structure and spatial distribution of fish populations. Fisheries. 2004;29(8):23-32.

35. Dwivedi AC, Nautiyal P. Population dynamics of important fishes in the Vindhyan region, India. LAP LAMBERT Academic Publishing $\mathrm{GmbH} \&$ Co. KG, Dudweiler Landstr. 99, 66123 Saarbrucken, Germany. 2010; 220 p.

36. Mayank P, Tyagi RK, Dwivedi AC. Studies on age, growth and age composition of commercially important fish species, Cirrhinus mrigala (Hamilton, 1822) from the tributary of the Ganga river, India. European Journal of Experimental Biology. 2015;5(2):16-21.

37. Sarkar UK, Negi RS, Deepak PK. Age structure of Indian carp Labeo rohita (Hamilton Buchanan) from different wild populations. Environmental Ecology. 2006;24:803-808.

38. Dwivedi AC. Age structure of some commercially exploited fish stocks of the Ganga river system (Banda-Mirzapur section). Ph. D. thesis submitted to Department of Zoology, University of Allahabad, Prayagraj, (Uttar Pradesh). 2006; p.138.

39. Imran S, Jha DN, Thakur S, et al. Age structure of Labeo calbasu (Hamilton 1822) from the river Yamuna. Journal of the Inland Fisheries Society of India. 2015;47(2):81-85. 